\title{
Carcinoma Ex-pleomorphic Adenoma: A Case for Cure
}

\author{
Champion V Srinivas
}

\begin{abstract}
Carcinoma ex-pleomorphic adenoma (CXPA) is an aggressive salivary gland malignant tumor. Diagnosis is difficult as the residual-mixed tumor is small and poorly understood due to the presence of various subtypes. Adenoma carcinoma and salivary duct carcinoma are two common subtypes. Prognostic factors are tumor size, grade, and clinical and pathological stages.

Keywords: CAXP, Malignancy, Prognosis, Salivary gland.

International Journal of Head and Neck Surgery (2020): 10.5005/jp-journals-10001-1351
\end{abstract}

\section{INTRODUCTION}

Carcinoma ex-pleomorphic adenoma (CXPA) is rare, very aggressive, and poorly understood malignancy that occurs in the salivary glands. In CXPA, an epithelial malignancy develops with a primary or recurrent benign pleomorphic adenoma. Metastasis from this tumor consists of carcinomatous elements alone. CXPA is a highgrade carcinoma with metastasis. In addition to CXPA, two other malignant-mixed tumors occur. One is a benign-mixed tumor that metastasizes as a benign tumor. The other is carcinosarcoma in which the primary tumor and a malignant mesenchymal tumor. CXPA accounts for $3.6 \%$ of all salivary neoplasm. High-grade sarcoma ex-pleomorphic adenoma is the latest entity. Long-standing tumors are malignant change prone. Malignant changes can occur due to genetic instabilities.

\section{Symptoms/Clinical Findings}

The CXPA presents as an asymptomatic mass, occasionally with pain and dysphagia due to the presence of a mass in the paraphargngeal space. The mean size of the tumor ranges from $1 \mathrm{~cm}$ to $17 \mathrm{~cm}$.

\section{Case Description}

A 47-year-old female (Fig. 1) presented with swelling in the oral cavity and was earlier treated with homeopathy for 2 months. On examination, the tonsil was found to be pushed medially into the

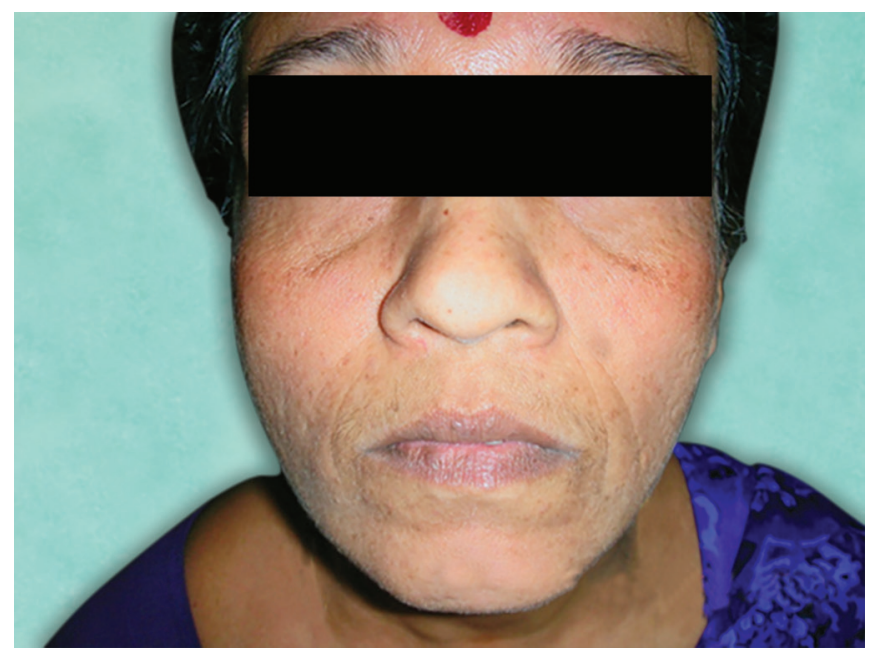

Fig. 1: Frontal profile of the patient
Department of ENT and Head and Neck Surgery, Dr BR Ambedkar Medical College, Bengaluru, Karnataka, India

Corresponding Author: Champion V Srinivas, Department of ENT and Head and Neck Surgery, Dr BR Ambedkar Medical College, Bengaluru, Karnataka, India, e-mail: game_sri@yahoo.com

How to cite this article: Srinivas CV. Carcinoma Ex-pleomorphic Adenoma: A Case for Cure. Int J Head Neck Surg 2020;11(2):32-35.

Source of support: Nil

Conflict of interest: None

oropharynx. Clinically apart from this, there were no other findings and neck examination revealed no lymph nodes. The patient was subjected to fine needle aspiration cytology (FNAC) of the mass.

\section{Fine Needle Aspiration Cytology}

Moderate cellular aspirate comprises loosely cohesive clusters of epithelial cells in a myxoid (mucoid) background. Flame cells had a squamoid appearance. The cells had moderate to abundant cytoplasm. Some had finely vacuolated cytoplasm. Also seen were foamy macrophages and multinucleate giant cell. Cells exhibit moderate anisonucleosis and conspicuous nucleoli. Occasional spindle-celled stromal fragments were seen. Features were suggestive of pleomorphic adenoma of minor salivary in the right parapharngeal area. Excision biopsy was suggested to rule out mucoepidermoid or acinic cell neoplasm.

\section{Computed Tomography Scan}

The spiral computed tomography (CT) scan of the neck was done with and without contrast revealing a large well-marginated mass in the right paraorophargeal space (Figs 2 and 3 ). The mass showed mild heterogeneous enhancement with small necrotic areas. The mass was displaced to the right lateral oropharyngeal wall and tonsillar fossa medially with mild narrowing of the airway (Fig. 4). Pterygoid muscles were compressed. No obvious continuation of mass is seen close to the deep lobe of the right parotid gland. The mass measured about $3.75 \times 3.4 \mathrm{~cm}$. The impression was a large mass in the right paraorophagngeal space that could be accessory salivary gland adenoma.

\section{Surgical Notes}

Under general anaesthesia (GA), right submandibular curvilinear incisions were taken (Fig. 5). Subplatysmal plane obtained (Fig. 6).

(c) The Author(s). 2020 Open Access This article is distributed under the terms of the Creative Commons Attribution 4.0 International License (https://creativecommons. org/licenses/by-nc/4.0/), which permits unrestricted use, distribution, and non-commercial reproduction in any medium, provided you give appropriate credit to the original author(s) and the source, provide a link to the Creative Commons license, and indicate if changes were made. The Creative Commons Public Domain Dedication waiver (http://creativecommons.org/publicdomain/zero/1.0/) applies to the data made available in this article, unless otherwise stated. 


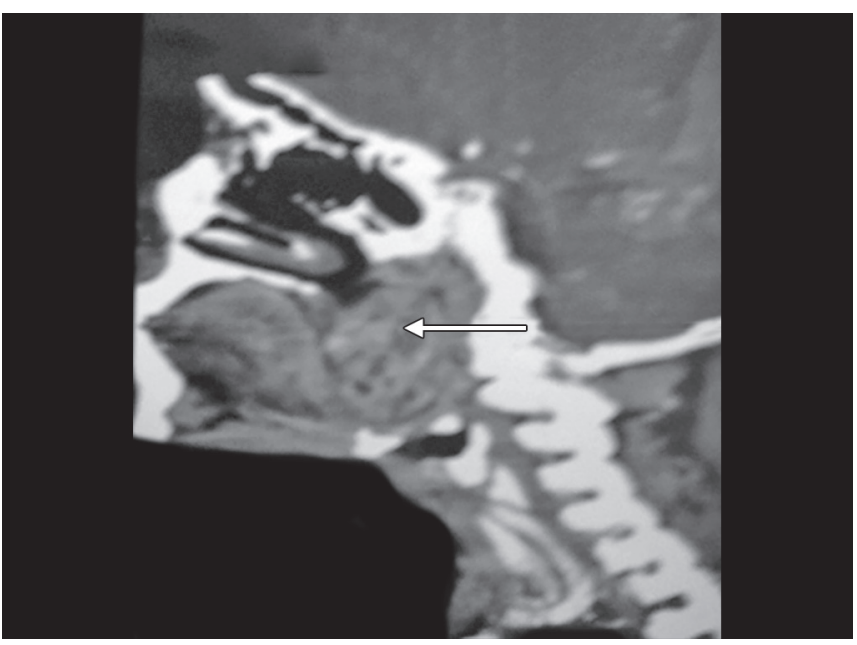

Fig. 2: Computed tomography scan showing tumor

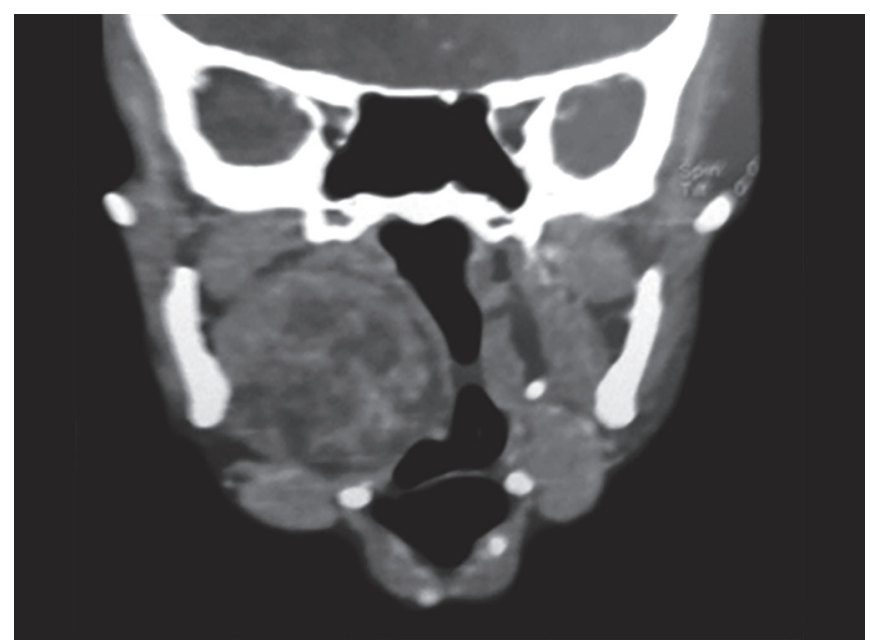

Fig. 4: Computed tomography scan showing medial area displacement of tonsillar fossa

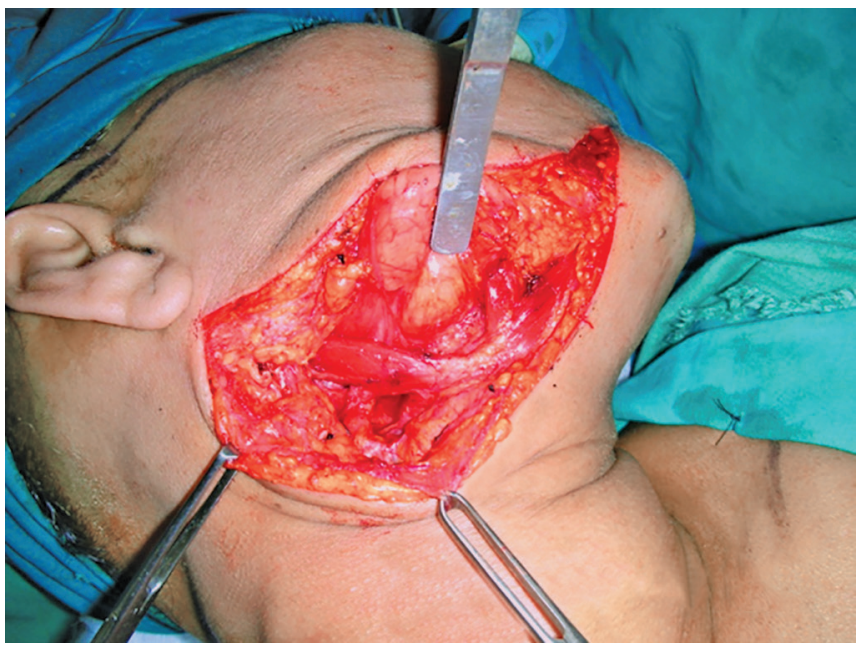

Fig. 6: Dissection

Submandibular gland delineated (Fig. 7). Digastric muscles cut. Mylohyoid delineated, and external carotid vessels were pushed away from the site of the mass (Fig. 8). A well-defined encapsulated adenoma was dissected (Figs 9 and 10). The wound was closed in layers.

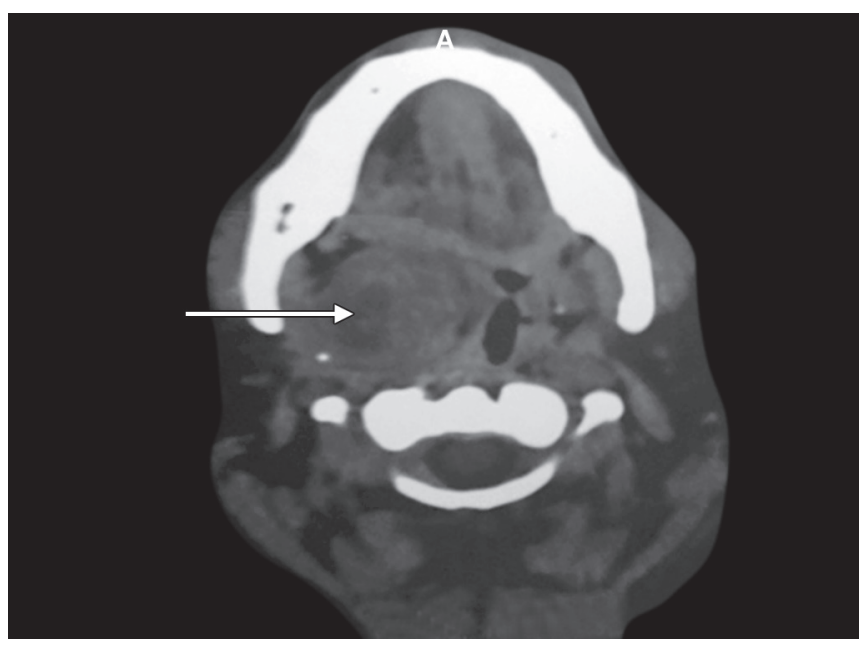

Fig. 3: Tumor in the right parapharyngeal space

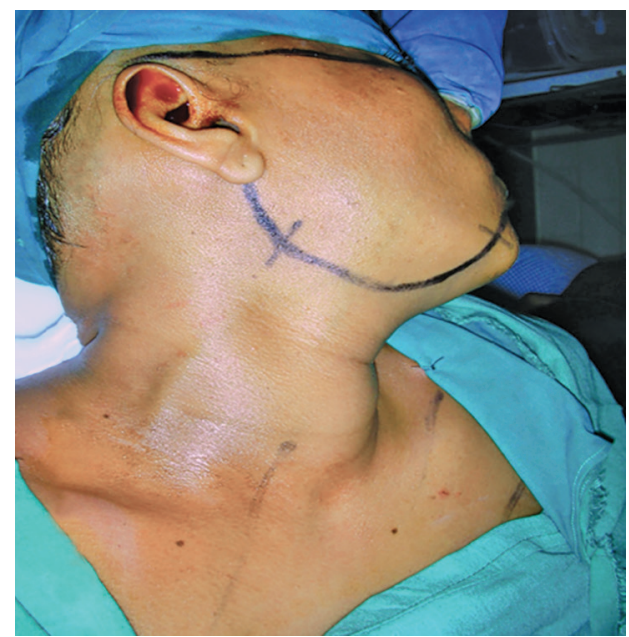

Fig. 5: Right lateral pharyngeal approach

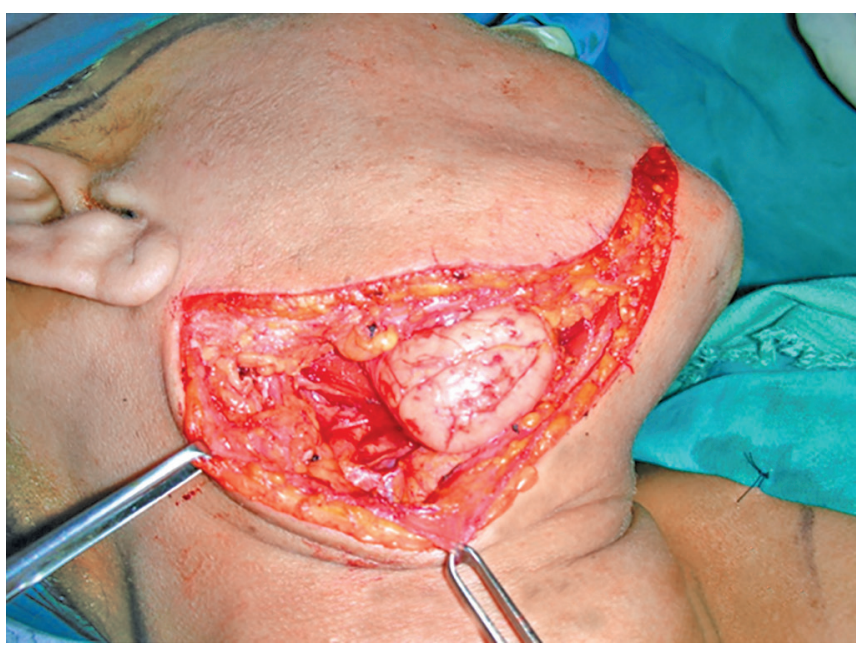

Fig. 7: Submandibular gland

\section{Histopathology}

Initially, it was reported as pleomorphic adenoma with mucoepidermoid carcinoma of the salivary gland supported by the following features: well-encapsulated tumor mass, proliferative 


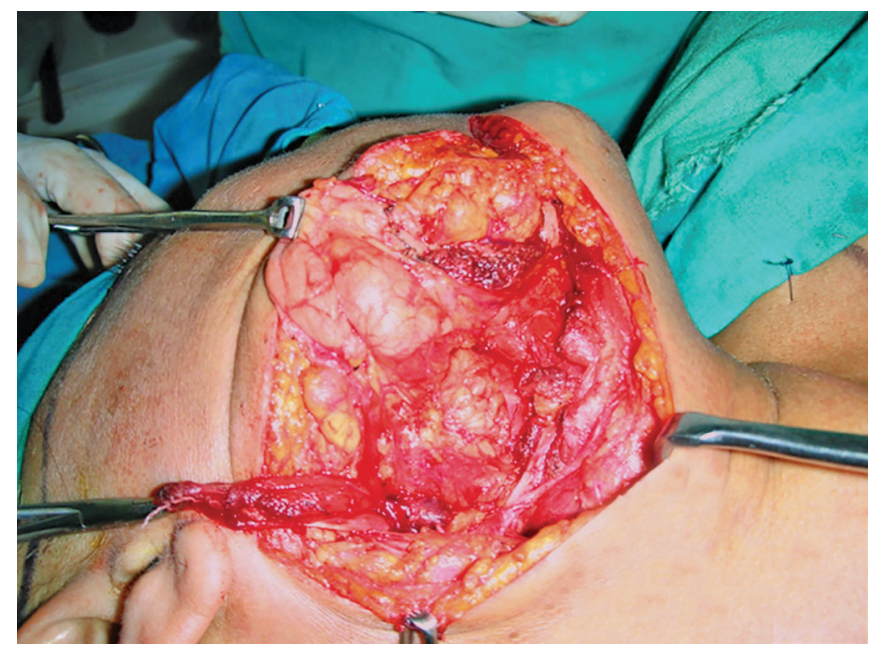

Fig. 8: Tumor in the parapharyngeal space

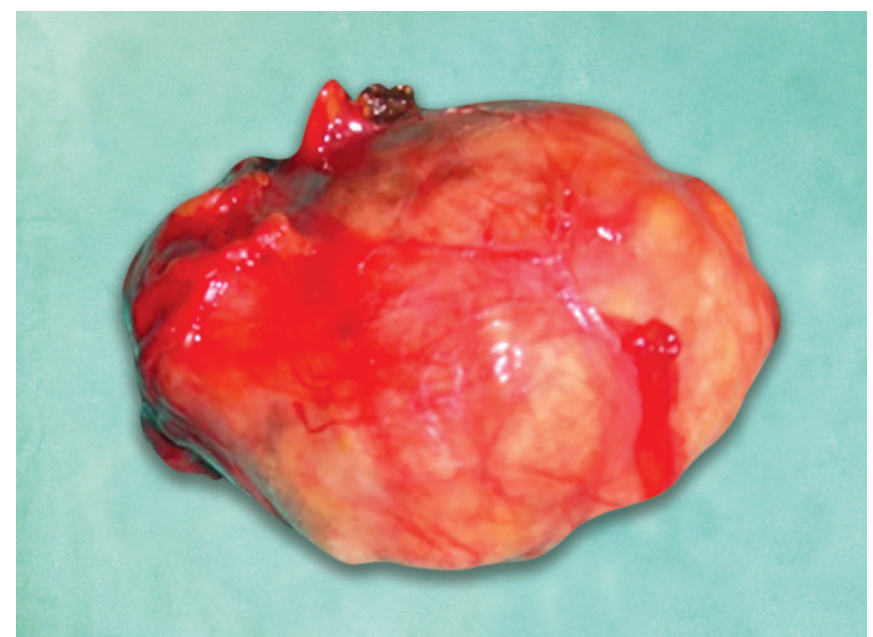

Fig. 10: Dissected specimen

epithelial cells, squamoid in nature, and arranged in nests surrounded by mucoid and myxoid areas, with cystic changes at places showing oncocytic change and chronic inflammatory infiltrate. The capsule is infiltrated by squamoid tumor cells but not beyond the capsule.

Another histological review was taken which showed an evidence of neoplastic cells comprising epithelial and myoepithelial cells. Cells were arranged in the form of ducts, acini, irregular, tubules, sheets, and nests. There were cystic structures lined by neoplastic cells. There are small to large cysts and disciform patterns lined by squamoid and mucous secreting cells. These areas show features of mucoepidermoid carcinoma: the stroma is abundant, loose with pseudocartilage and myxoid areas. Focal chronic inflammatory cell infiltrate was noted in the stroma. Hence, a diagnosis of CXPA-minor salivary gland-was made.

\section{Postoperative Management}

After this operation, the patient's wound healed well and the patient was subjected to radiotherapy with a dose of $55 \mathrm{~g} / 27$ cycles at the Department of Radio-oncology, for which she had a minimal skin reaction. Ap/BI with computerized c7 planning. The post follow-up showed no residual, recurrent 8.5 years postop. No e/o recurrent tumor and disease.

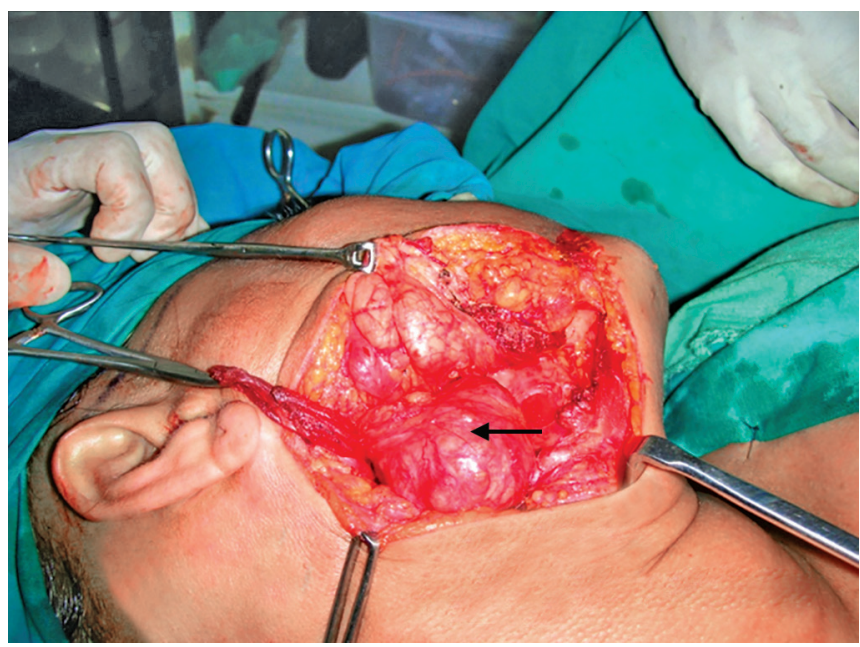

Fig. 9: Intact capsule

\section{Discussion}

The CXPA is an aggressive malignancy. Regional metastasis and mortality are high. It was difficult to diagnose as the mixed tumor component is small and, overlooked, malignant component may be difficult to classify. Pathogenesis is controversial. One school believed that the tumor was malignant from the onset. ${ }^{1}$ Another group proved carcinomatous transformation of a benign-mixed tumor. ${ }^{2}$ Up to a 100 cut may be required to find a small mixed tumor in a salivary gland carcinoma. ${ }^{3} \mathrm{~A}$ residual-mixed tumor component should be looked for. ${ }^{4}$ It has been reported that if the carcinomatous components are combined within the benign-mixed tumor capsule, the prognosis is excellent. ${ }^{5}$ Perineural invasion, lymph node metastasis, and positive margins were all poor prognostic factors. ${ }^{6}$ Timely removal of all masses should eliminate almost half of all the CXPA tumors; optimal diagnosis and treatment can be achieved only by close communication between the surgeon and the pathologist, and adequate surgery by an experienced oncologist. The role of chemotherapy is determined based on the histological assistance from a radiation oncologist.

Tumors that invade beyond the capsule into the surrounding tissue by less than $1.5 \mathrm{~cm}$ are known as minimally invasive. These patients have an excellent prognosis. The tumor going beyond $1.5 \mathrm{~cm}$ is known as invasive. In such patients, the prognosis varies in accordance with the tumor shape and the grade. The grade of cells seen in cancerous epithelial components varies from well differentiated to poorly differentiate to anaplastic depending on the type of cancer. Most carcinomas are high grade, but some are low grade. A mucoepidermoid CXPA is histologically categorized as being of low, intermediate, or high grade histologically. Perineural invasion and angiovascular invasion are commonly encountered in invasive types. Necrosis is prominent in high-grade types. Metastasis may occur in the lymph nodes, the bone, and the brain (vertebral bodies specially).

\section{Immunohistochemistry}

Tumor markers are described for pleomorphic adenoma. Specific additional markers for CXPA —immunoreactivity for p53-are used to differentiate pleomorphic adenoma and CXPA. ${ }^{7-10}$ Her2 (c-ab b-2) has been used, along with cyclin A. ${ }^{10-13}$ X-linked inhibition of apoptosis protein (XIAP) is also associated with aggressive behavior of CXPA. ${ }^{14}$ 


\section{Genetics}

Rearrangement of chromosome $8 \mathrm{q} / 12$ and alternation in chromosome 12q13-15 with amplification of AMGIC, HMGA2, and mpm3 may contribute to malignant transformation. ${ }^{15} \mathrm{p} 53$ alternations and over expressions are seen in the development of CXPA. ${ }^{10}$

- Stage I disease: excellent prognosis

- Stage IV disease: poor prognosis.

Undifferentiated carcinoma has the worst survival rate. Polymorphous low-grade adenocarcinomas have a high survival rate.

\section{Differential Diagnosis (DD)}

- Cellular monomorphic adenoma

- Cellular pleomorphic adenoma

- Infarcted pleomorphic adenoma

- Pleomorphic adenoma

\section{Conclusion}

The CXPA is a tumor, which when detected early and when we have a high suspicion of malignancy, can be totally recurrence free if properly managed with multimodality form of treatment-a case for cure.

\section{References}

1. Gerughty RM, Scofield HH, et al. Malignant mixed tumors of salivary gland origin. Cancer 1969;24:471-486. DOI: 10.1002/1097-0142(196909)24:3<471::AID-CNCR2820240309>3.0.CO;2-0.

2. Beahrs $\mathrm{OH}$, Woolner LB, et al. Carcinomatous transformation of mixed tumors of the parotid gland. AMA Arch Surg 1957;75:605-614. DOI: 10.1001/archsurg.1957.01280160115015.

3. Foote FW, Frazell EL. Tumors of the major salivary glands. Cancer 1953;6:1065-1133. DOI: 10.1002/1097-0142(195311)6:6<1065::AIDCNCR2820060602>3.0.CO;2-0.

4. Lewis JE, McKinney BC, etal. Salivary duct carcinoma. Clinicopathologic and immunohistochemical review of 26 cases. Cancer 1996;77: 223-230. DOI: 10.1002/(SICI)1097-0142(19960115)77:2<223::AIDCNCR1>3.0.CO;2-N.
5. Patey $\mathrm{DH}$, Thackray AC, et al. Malignant disease of the parotid. $\mathrm{Br} \mathrm{J}$ Cancer 1965;19:712-737. DOI: 10.1038/bjc.1965.84.

6. LiVolsi VA, Perzin KH. Malignant mixed tumors arising in salivary glands. I. Carcinomas arising in benign mixed tumors: a clinicopathologic study. Cancer 1977;39:2209-2230. DOI: 10.1002/1097-0142(197705)39:5<2209::AID-CNCR2820390540> 3.0.CO;2-8.

7. Ihrler $S$, Weiler $C$, et al. Intraductal carcinoma is the precursor of carcinoma ex pleomorphic adenoma and is often associated with dysfunctional p53. Histopathology 2007 Sep;51(3):362-371. DOI: 10.1111/j.1365-2559.2007.02736.x.

8. Brandwein $M$, Huvos AG, et al. Noninvasive and minimally invasive carcinoma ex mixed tumor: a clinicopathologic and ploidy study of 12 patients with major salivary tumors of low (or no?) malignant potential. Oral Surg Oral Med Oral Pathol Oral Radiol Endod 1996 Jun;81(6):655-664. DOI: 10.1016/S1079-2104(96)80071-0.

9. Deguchi $\mathrm{H}$, Hamano $\mathrm{H}$, et al. c-myc, ras p21 and p53 expression in pleomorphic adenoma and its malignant form of the human salivary glands. Acta Pathol Jpn 1993 Jul-Aug;43(7-8):413-422. DOI: 10.1111/j.1440-1827.1993.tb01152.x.

10. Righi $P D, L i Y Q$, et al. The role of the $p 53$ gene in the malignant transformation of pleomorphic adenomas of the parotid gland. Anticancer Res 1994 Sep-Oct;14(5B):2253-2257.

11. Ohtaké $S$, Cheng J, et al. Precancerous foci in pleomorphic adenoma of the salivary gland: recognition of focal carcinoma and atypical tumor cells by P53 immunohistochemistry. J Oral Pathol Med 2002 Nov;31(10):590-597. DOI: 10.1034/j.1600-0714.2002.00040.x.

12. Freitas LL, Araujo VC, et al. Biomarker analysis in carcinoma ex pleomorphic adenoma at an early phase of carcinomatous transformation. Int J Surg Pathol 2005 Oct;13(4):337-342. DOI: $10.1177 / 106689690501300405$.

13. Lewis JE, Olsen KD, et al. Carcinoma ex pleomorphic adenoma: pathologic analysis of 73 cases. Hum Pathol 2001 Jun;32(6):596-604. DOI: 10.1053/hupa.2001.25000.

14. Rosa JC, Fonseca I, et al. Immunohistochemical study of c-erbB-2 expression in carcinoma ex-pleomorphic adenoma. Histopathology 1996 Mar;28(3):247-252. DOI: 10.1046/j.1365-2559.1996.d01-424.x.

15. Patel RS, Hughes CW, et al. Cyclin A expression and its diagnostic value in pleomorphic adenoma and carcinoma expleomorphic adenoma of the parotid gland. Histopathology 2007 Jul;51(1):21-25. DOI: 10.1111/j.1365-2559.2007.02729.x. 